\title{
AMOR Y SIMBOLISMO EN LA OBRA DE CHAUCER
}

M." SOledad Vila

Universidad Politécnica de Madrid

El término símbolo se usa para indicar los fenómenos más heterogéneos y, en un sentido más amplio, este término se aplica a todo aquello que siendo conocido remite a otro, estableciendo una asociación entre ambos, así por ejemplo el humo respecto al fuego. Sirve para representar algo que no se podría explicar de una manera más clara o significativa. mostrando una realidad que ninguna otra manifestación está en condiciones de revelar. El lenguaje es la primera realización simbólica, ya que en un cierto sentido, todo lo linguístico es simbólico. $\mathrm{El}$ símbolo posee un doble sentido. Por un lado es una cosa concreta y por otro posee un aspecto alusivo y figurado, es decir, por una parte pertenece al mundo físico del ser y por otra se engloba en el mundo humano de la significación.

Chaucer considera en The House of Fame, que la correspondencia entre las palabras y la persona que las pronuncia es tan grande que una vez que las palabras penetran en la Casa de la Fama (lugar que sitúa entre el cielo y la tierra), pueden transformarse en los propios individuos que las pronunciaron. La conciencia dispone de dos maneras de poder representarse el mundo: una directa, como simple percepción o sensación producida y otra indirecta o simbólica, que en realidad es una imagen en el sentido más amplio de la palabra. Pero existen realidades difíciles de representar y éstas van a ser el dominio predilecto del simbolismo. Al no poder producirse estos fenómenos, la imagen simbólica es una transfiguración de una cosa que tiene un sentido totalmente abstracto, lo que le hace aparecer con un cierto sentido secreto. Todo símbolo posee tres dimensiones concretas: es al mismo tiempo cósmico, ya que proce- 
de su representación del mundo visible que nos rodea; onírico, puesto que se apoya en los recuerdos que aparecen en nuestros sueños y pensamientos más íntimos, y, por último, poético al recurrir a un lenguaje concreto y personal. Las transformaciones de sonidos en personas, de luces en otros seres y de unas especies en otras, corresponden, en términos generales, al gran simbolismo de la inversión y a la diferencia existente entre lo primigenio y el mundo actual. En el simbolismo todo posee significado, todo es de alguna forma intencional, produciendo un efecto o huella que puede ser objeto de comprensión e interpretación. Las discusiones en torno a las posibilidades de interpretación han existido siempre. Los símbolos tienen un origen histórico, cósmico y natural, y pueden ser interpretados desde un punto de vista psicológico y mítico. La descripción que hace Chaucer en The Book of the Duchess de la joven duquesa Blanche tiene muchas connotaciones con la Virgen María, al indicar que su garganta semejaba una torre de marfil. La torre simboliza por su aspecto cerrado y amurallado a la Virgen, como nos muestran numerosas pinturas y grabados, y como lo recuerdan las propias letanías en las que se alaba su elevación de espíritu por encima de todos los mortales. El mismo nombre de Blanca simboliza la pureza del alma representando el estado celeste, recuerda la Purísima Concepción concebida sin pecado alguno, y al igual que ella, estaba llena de gracia.

* Hyr throte, as I have now memoyre,

Semed a round tour of yvoyre, Of good gretnesse, and noght to gret. «And goode faire White she het; *

En The House of Fame, Chaucer cuenta los amores desgraciados de la reina Dido, después de haber efectuado una breve descripción del templo de Venus. Tras escapar del templo del amor, aparece en un desierto que simboliza una alternativa inmediata al lugar descrito anteriormente, siendo rescatado Chaucer por el águila dorada que le enseña el orden de la naturaleza. El águila tiene el papel de mensajero celestial y representa el ascenso de las súplicas hacia Dios y el descenso de las gracias sobre los mortales. La imagen del águila llevando al poeta entre sus garras nos indica la victoria del principio paterno de los instintos amorosos. Se establece una comparación humorística entre la sabiduría del águila y la ignorancia del poeta, quien, cuando se le pregunta por el motivo de su viaje a los cielos, contesta que está tratando de escuchar nuevas noticias sobre el amor y otros sucesos felices, siendo ésta la causa de su visita a la Casa de la Fama y posteriormente a la del Rumor. 
"Of love or suche thynges glade
For certeynly he that me made
To comen hyder, seyde me,
$Y$ shulde bothe here and se,
In this place, wonder thynges;"

(H.F. 1889-1893).

En The Parliament of Fowls se establece un debate entre el amor cortesano y el amor popular. La madre Naturaleza interviene en la discusión dando el plazo de un año para que se decida la dama, en este caso representada por un águila, a los requerimientos amorosos de sus tres pretendientes, mientras los demás pájaros eligen rápidamente a sus respectivas parejas. entonando cantos de alegría en el día de San Valentín. De la misma manera que en The House of Fame Chaucer convierte el viaje del águila a través de los cielos en un mensaje puramente espiritual, en The Parliament of Fowls critica la postura que adoptan las diferentes clases sociales ante el problema del amor. Los pajarillos, antes de echarse a volar, comienzan a cantar para honrar a la Naturaleza, comparando los esplendorosos días del verano con las oscuras noches del invierno, enfrentando así el enamoramiento con el desamor.

\begin{abstract}
*Now welcome, somer, with thy sonne softe,
That hast this wintres wedres overshake, And driven away the longue nyghtes blake! «Saynt Valentyn, that art ful hy on-lofte, Thus syngen smale foules for thy sake;

Now welcome, somer, with thy sonne softe, That hast this wintres wedres overshake».
\end{abstract}

(P.F. 680-686)

En The Legend of Good Women se establece un emparejamiento entre la figura del poeta y la reina Alceste que actúa de musa, mientras el rey del amor desempeña el papel de critico. La reina impone a Chaucer como penitencia que emplee la mayor parte de su vida en escribir interminables leyendas sobre las «santas» mujeres. Tanto el dios del amor como la reina Alceste. son representaciones abstractas que no pueden existir fuera del sueño de Chaucer. El dios del amor sintetiza las verdades terrenales y religiosas, pareciendo un «Cupido cristiano». Chaucer, al tratar de producir esta síntesis, establece una estrecha relación entre Dios y otras identificaciones. Aun cuando el dios del amor no es el sol, lo lleva dibujado en su emblema. El brillo de su cara esta relacionado 
con el verdadero sol, deslumbrando con su resplandor los cansados ojos del poeta.

«For sikerly his face shon so bryghte

That with the glem astoned was the syghte;

A furlong-wey I myhte hym not beholde.*

(L.G.W. G 163-165)

El dios del amor portaba entre sus manos dos afilados dardos, llevando alas al igual que el clásico Cupido, pero en oposición a éste no era ciego:

"But at the laste in hande I saw hym holde

Two firy dartes, as the gleedes rede,

And aungellych hys winges gan he sprede.

And al be that men seyn that blynd is he,

Algate me thoughte he myghte wel yse;

(L.G.W. G 166-170)

A través de este nuevo Cupido, Chaucer trata de reconciliar el amor humano con el divino, en especial los amores clásicos que muestran gran pasión y caridad cristiana. Al describir a Alceste con sus vestiduras reales, toda de verde y con una corona blanca de margaritas sobre sus dorados cabellos, simboliza una figura real y literaria. Por un lado representa a la reina Alceste que fue capaz, por amor a su esposo, de descender a los infiernos de donde fue rescatada por Hércules. Por otro, simboliza la flor de la margarita de la cual Chaucer y otros poetas medievales eran muy devotos por ser una imitación del sol de quien depende la vida.

En muchos episodios de The Canterbury Tales aparecen sucesos que tienen un claro simbolismo. Así, en «The Nun's Priest's Tale», en el que el ataque del zorro a Chantecler puede ser interpretado como la tentación que sufrí Adán por el demonio convertido en serpiente y la pobre viuda es la representación de la Iglesia.

En «The Miller's Tale», cuando el molinero es víctima en la parodia del falso «diluvio», se despierta sobresaltado al oir el grito de jagua! que lanzaba Nicolás al quemarse con el hierro incandescente que empuñaba el apasionado Absalón. Este hecho es una clara alusión al poder que Dios ha dado al hombre de absolver los pecados mediante el bautismo. 
En «The Merchant's Tale», la lozana Mayo fue seducida por su criado Damián, delante de su marido, el viejo Enero, que en ese mismo instante recobró la vista, mientras su mujer afirmaba que estaba desvariando. Este suceso es una representación de la caída de Adán y Eva en el Paraíso, y el hecho de que el viejo Enero recupere la vista es una señal de revelación, ya que la ceguera que tenía es una imagen de la que se sirve el autor para indicamos su carencia de conocimientos.

La palabra luz ha sido identificada tradicionalmente con el espíritu; es también la manifestación de la moralidad y de la intelectualidad. Se puede, por tanto, afirmar que la luz es la fuerza creadora que movió a nuestro gran poeta a escribir tan dilatada obra. Para algunos, el sonido es la primera cosa creada, lo que motivó o dio origen a todos los fenómenos comenzando por la luz, el aire, o el fuego. En The House of Fame se percibe esta luz de inspiración deslumbrante que expande sus refulgentes rayos y los proyecta en otros poetas venideros. El rumor transformado en fama es lo que Chaucer, sin duda. pensaba alcanzar al escribir sobre el amor.

El profeta se describe como escritor de temas amorosos, nos dice cómo estudia hasta bien entrada la noche para así adquirir esa luz creadora de la sabiduría, puesto que tiene que trabajar durante el día y, como recompensa a sus desvelos es conducido por un águila hasta la Casa de la Fama, donde recibirá toda clase de noticias sobre la experiencia en las distintas demostraciones de amor. El águila divertida ante el incrédulo escritor, le lleva a contemplar el gran espectáculo que tenía ante sus ojos, recibiendo la luz para comprender las maravillas del universo ante las que queda absorto y exclama:

«O God! $»$, quod $y$, «that made Adam, Moche ys thy myght and thy noblesse!»

(H.F. 970-971)

Chaucer, cuando el águila se muestra ansiosa por informarle sobre los nombres de las estrellas, el poeta afirma ser demasiado viejo para recibir la luz del conocimiento. El águila le recrimina diciéndole cuán útil es ese conocimiento y una manera de obtenerlo será «when thou redest poetrie» (H.F. 1001). Chaucer contestó que confiaba plenamente en las palabras del escritor y que, en cualquier caso, estaba tan cerca de las estrellas que le cegaban si miraba hacia ellas. Esta ceguera que acusaba el poeta al contemplar los deslumbrantes astros podría simbolizar la ceguera del entendimiento por negarse a ver la luz, por lo que el águila le conduce de nuevo a la Casa de la Fama. Dicha ave, representa un conjunto de conocimientos que se exponen a lo largo del poema, siendo también un 
símbolo del principio espiritual que se identifica con el sol, que representa el calor vital y la luz, el origen del día. Su vida, por eso, transcurre a pleno sol, de ahí que sus rayos poderosos irradien sus alas dándolas el color del oro, sirviendo por tanto de contrapeso a la oscuridad de la noche en la que se producen los sueños. La función del águila sirve para corregir las fuerzas oscuras impulsando con ello los altos destinos espirituales y morales. En este sentido, el dios Júpiter ensalza el trabajo humilde y la virtud, junto con el trabajo penoso que produce dolor de cabeza al escribir poemas de amor:

"Wherfore, also God me blesse, Joves halt hyt gret humblesse, And vertu eke, that thou wolt make A-nyght ful ofte thyn hed to ake In thy studye, so thou writest,

(H.F. 629-633)

Al igual que las cosas que proceden de la Naturaleza, los sonidos u objetos inanimados se dirigen desde la base o lugar desde donde se producen hacia su casa natural, siendo este lugar la morada de «Lady Fame».

*As I have before preved the, Hyt seweth, every soun, parde, Moveth kyndely to pace

Al up into kyndely place. And this place of which I telle, Ther as Fame lyst to duelle,

(H.F. 839-844)

Tras explicar el autor que había ido a la Casa de la Fama para tener más noticias sobre «love, or suche thynges glade» (H.F. 1889), es conducido a la Casa del Rumor, formada toda ella por ramas de árboles entrelazadas, apareciendo grandes agujeros por donde dejaban escapar un gran sonido. Vio tantas cosas nuevas sobre el amor que se consolo por haber permanecido en la luz de la ignorancia y la felicidad desde que la diosa Fortuna había destruido la paz de su corazón.

Su tristeza puede llegar a la frustración de su poesía, causada por la presión a la que se ve sometido a diario llevando las cuentas de sus negocios , en 
vez de gozar de la lectura. Estas extrañas visiones y noticias o historias de amor, servirán de recompensa al que le ha sido negada la libertad y el conocimiento, más que a aquel que ha sido desgraciado en el amor.

Existe una relación de solidaridad entre la luz brillante del conocimiento y la superación de la condición humana. La mística de la luz es bastante compleja. Existe ante todo la idea básica de que la luz es creadora; la luz es procreación. El ser se manifiesta por la luz y el hombre toma conocimiento del ser mediante una experiencia de luz sobrenatural. La luz que brilla en lo alto del cielo, por encima del mundo y de las cosas, es la misma que brilla en el interior del hombre. El resplandor de esta luz puede cegarle, permitiéndole un mayor conocimiento de su propio yo:

«And eke they shynen here so bryghte,

Hyt shulde shenden al my syghte,

To loke on hem.* «That may wel be,

(H.F. 1015-1017)

La toma de conciencia de la identidad entre la luz interior y la que brilla en todo lo alto, está acompañada a veces por otros fenómenos, tales como la audición de sonidos místicos.

*A while, and than he gan to crye,

That never herde I thing so hye,

(H.F. 1019-1020)

La luz no es simplemente un acto de conocimiento metafísico, sino una experiencia más profunda en la que el hombre compromete su propia existencia. El conocimiento supremo determina una modificación del propio ser, de la oscuridad a la luz y de la muerte a la inmortalidad. En el momento de la muerte, el alma se eleva hacia los rayos del sol aproximándose a la puerta del mundo, y sólo aquellos que posean conocimientos podrán entrar, pero la puerta permanecerá cerrada para los que no saben. El momento de la iluminación es consecuente con la situación del hombre que se ha liberado de todos los condicionamientos que limitan su saber. Esta luz es clara, pura, es decir, no sólo sin mancha ni sombra, sino sin ningún color ni determinación, por lo que se le ha dado en llamar vacío universal. El entendimiento de este vacío, es un acto instantáneo y reflejo de iluminación, comparable al relámpago deslumbrador que repentinamente rasga las tinieblas, sin solución de continuidad en el tiempo 
que la precede y el instante en que se realiza. La ruptura de nivel realizada por la iluminación se corresponde con un enorme ruido que precede la llegada de Chaucer y el águila a la Casa de la Fama.

*In Fames Hous, full of tydynges, Bothe of feir speche and chidynges. And of fals and soth compouned."

(H.F. 1027-1029)

Desde el punto de vista natural, el sonido representado por el trueno es posterior al relámpago, pero hay doctrinas tradicionales que consideran al sonido como la primera cosa creada que dio origen a todas las cosas, comenzando por la luz, el aire y el fuego.

En sus comienzos, el mundo estaba cubierto de agua y el Gran Dios Creador permanecía entonces en el interior de una roca. El hombre parece considerar a las piedras y a las rocas como el origen de la vida humana, algo más elevado que las tierras que son inferiores. Por su mayor disgregación son madre de la vida vegetal y animal. La roca tiene también un significado místico en relación con el sonido que produce al ser golpeada y con la unidad que presenta en virtud de su solidez y cohesión. Esta idea está reflejada en los siguientes versos:

"And what soun is it lyk* quod hee.

*Peter! lyk betynge of the see,*

*Quod y, *ayen the roches holowe,

Whan tempest doth the shippes swalowe;

(H.F. 1033-1036)

La transformación de los sonidos en rumores y seres humanos es una consecuencia de la ambición del hombre, ya que los individuos aparecen confundidos con sus propios deseos y súplicas, entremezclándose la verdad con la mentira, llegando a ser todo confuso.

El Templo de Venus, el Castillo de la Fama y la Casa del Rumor, tienen un denominador común: la fragilidad. El amor,la fama y el rumor, representan existencias efímeras ligadas alegóricamente al rápido transcurso del tiempo. El rumor representa opiniones contrastadas y yuxtapuestas a la Fama. Estas aumentan o disminuyen con las vicisitudes de la Fortuna, que puede compararse 
en términos generales con todas las cosas de la Naturaleza, no limitándose exclusivamente al amor.

El rumor, como todos los sonidos, se transmite en forma de ondas, al igual que las mareas que fluyen sobre las costas, acercándose y alejándose de las rocas. De forma alegórica, el sonido retumba en los rincones, apagándose y elevándose en cada ángulo de la casa. Existe una correspondencia de la casa con el cuerpo humano y el castillo como símbolo del alma. El castillo, al estar situado en la cima de un monte, le añade un importante componente relativo a su mayor altura e inmaterialidad.

El castillo luminoso que aparece ante el viajero, simboliza la adaptación al aspecto espiritual de las cosas, ante cuya visión desaparecen los aspectos materiales de la vida, tales como: la fatiga, el dolor, la riqueza.

El templo que refulge bajo los rayos solares es la realización de lo imposible y la materialización de lo inesperado. Las multitudes de mensajeros, peregrinos y suplicantes que acuden a la Casa del Rumor, no poseen una ambición tan desmedida como los que acuden a la Casa de la Fama y aparecen embebidos por sus propias súplicas que se confunden con los sonidos del lugar.

La llegada de un hombre de "grete auctoritee», impone el orden a esta confusa situación, siendo tan importante su presencia como la del águila que guía al poeta a la Casa de la Fama.

El mundo presenta una gran multiplicidad de imágenes simbólicas referentes a los distintos aspectos que pueda adoptar. Los sonidos, aún cuando no sean más que una expulsión de aire al pronunciarse las palabras, dichas en voz alta o baja, llenas o no de significado, tienen una estrecha relación con el pensamiento humano, al igual que el humo con el fuego:

"Soun ys noght but eyr ybroken, And every speche that ys spoken, Lowd or pryvee, foul or fair, In his substaunce ys but air: For as flaumbe ys but lyghted smoke, Ryght soo soun ys air ybroke."

(H.F. 765-770)

Júpiter, por mediación del águila hace dos revelaciones al poeta, la primera, indica que los sonidos, al llegar al interior de la Casa de la Fama, se convierten en palabras y éstas a su vez en poesía. Tras esta manifestación sobre la esencia de la poesía como algo ignoto e incomprensible por lo lejano, simboli- 
za la síntesis de lo desconocido, y explica que estos mismos sonidos se transforman en la propia imagen de la persona que los emite:

*Loo, to the Hous of Fame yonder,

Thou wost now how, cometh every speche;

Hyt nedeth noght eft the to teche.

But understond now ryght wel this,

Whan any speche ycomen ys

Up to the paleys, anon-ryght

Hyt wexeth lyk the same wight

Which that the word in erthe spak,

(H.F. 1070-1077)

Chaucer, nos describe a la joven Duquesa Blanche, al encontrarla en compañía de otras damas, aureolada de una radiante luz, tan brillante como el esplendoroso sol de verano y la de cualquiera de los siete planetas que pueblan el firmamento, identificándola con la condición de inmortalidad y belleza interior.

"Among these ladyes thus echon,

Soth to seyen y sawgh oon

Thas was lyk noon of the route;

For I dar swere, withoute doute,

That as the someres sonne bryght

Ys fairer, clerer, and hat A more lyght

Than any other planete in heven,"

(B.D. 817-823)

La luz no es sólo un acto de conocimiento metafísico, sino una experiencia más profunda en la que el hombre compromete su propio ser. Todo hombre puede pasar de la muerte a la inmortalidad, de la oscuridad a la luz y del no existir al ser; la luz se identifica, por tanto, con el propio ser y la inmortalidad. En el momento de la muerte, el alma inmortal se eleva hacia el cielo atraída por la brillante luz del sol, al igual que en The Book of the Duchess los ojos del caballero vestido de negro se sintieron atraídos hacia la blanca faz de su dama. 


\section{BIBLIOGRAFÍA}

BENNET, J.A.W. Chaucer's Book of Fame: An Exposition of The House. London: Clarendon Press. 1968.

Bortani, P. y J. MANn (eds.). The Cambridge Chaucer Companion. Cambridge: Cambridge University Press. 1987.

Bolton, W.F. (ed.). The Middle Ages. London: Sphere Books. 1986.

BREWER, D.S. (ed.). Chaucer the Critical Heritage. Vol. 1. 1385-1837. London: Routledge and Kegan Paul. 1978.

- Tradition and Innovation in Chaucer. New York: The MacMillan Press. 1982.

Condren, E.I. «The Historical Context of The Book of the Duchess: A New Hypothesis». Chaucer Review. Vol. 5. 1971. 195-212.

Harrington, N.T. «Chaucer's Merchant Tale»: Another Swing of the Pendulus». P.M.L.A. Vol. 86. 1981.

HowaRD, D.R. Chaucer his life his works his world. New York: Fawcet Columbina. 1989.

JORDAN, R.M. Chaucer's poetics and the modern reader. Berkeley: University of California Press. 1987.

KRUGER, J.F. «Passion and Order in Chaucer's Legend of Good Women». Chaucer Review. Vol. 23. 1989. 
RoBinSON, F.N. (ed.). The Works of Chaucer. Oxford: Oxford University Press. Fifth impression. 1957-1987.

SAlu, M. (ed. ). Essays on Troilus and Griseyde. Cambridge: Cambridge University Press. 1979.

SKEAT, W. W. The complete Works of Geoffrey Chaucer. 7 Vols. Oxford: Oxford University Press.1894-7; repr. 1972. 